\title{
Assessing Flood Risk Dynamics on the Oder River within the Context of Socio-Economic Consequences and Lasting Sustainable Development
}

\author{
Łukasz Szałata ${ }^{1 *}$, Łukasz Kuźmiński², Jerzy Zwoździak³ \\ ${ }^{1}$ Wrocław University of Technology, Pl. Grunwaldzki 9, 50-377 Wrocław, \\ Department of Environmental Engineering \\ ${ }^{2}$ Equation Chapter 1 Section 1 University of Economics in Wrocław, Department of Quantitative \\ Methods in Economics, Komandorska 118/120, 53-345 Wrocław, Poland \\ ${ }^{3}$ IMGW-PIB Warsaw Branch, ul. Podleśna 61, 00-001 Warsaw
}

Received: 9 June 2017

Accepted: 19 August 2017

\begin{abstract}
We carried out a probabilistic analysis of the dynamics of flood risks for the selected area of the Oder River basin. The authors based their risk dynamics assessment on results from the distributions of the maximum values for a selected hydrological characteristic, namely flow rate. On the basis of the daily flow data from 1994-2013 collected at a hydrological station on the Oder River in the town of Malczyce, 30-day flow maxima were selected individually for four five-year periods. Then, a probabilistic model of maximal flow was estimated on the basis of these peaks for each five-year period. The resulting models were used to estimate flood risks and analyze the dynamics of the studied area.
\end{abstract}

Keywords: flood risk, flow, extreme value distributions, Gumbel distribution, sustainable development

\section{Introduction}

The Lower Silesia Province is embedded in sustainable development based along the axis of the Oder River Basin, which is why it is extremely important to explain the relationship between its main components: the economy, society, and the environment. It is important to take into account the fact that the economy and society constitute systems dependent on the environment, therefore any action undertaken should stay within the tolerance of

*e-mail: Lukasz.szalata@pwr.edu.pl nature understood as nature's absorption capacity. The low level of public awareness of the intertwining between the economy, society, and the environment is one of the key barriers to a sustainable, balanced development and caring for the individual components of the environment, including water resources.

The main purpose of this article is to point out one of the mathematical methods based on the probabilistic models of extreme values as an effective tool to support management of the flood risk in reducing the potential socio-economic consequences. Ultimately, the application of the presented method gives a very realistic estimation of the possibility and location of flood risk. 


\section{Material and Methods}

The main purpose of the project is a probabilistic analysis carried out regarding the dynamics of flood risks for the selected area of the Oder River Basin using the chosen paradigm and research method described below.

\section{Choice of Paradigm}

The paradigm used in the following project can be defined as positivisms based on many scientific quantitative publications created by a qualified group of scientists who have solid data from many field-studies. The authors accept the theories and information from such sources to be carried out regarding the dynamics of flood risks for the selected area of the Oder River Basin by using new scientific calculations that affect sustainable development.

\section{Choice of Method}

In order to properly address this topic we decided to make quantitative research. Data collected via desk research included many results of scientific research in the field of flooding and environmental management under the circumstances. The project is based on quantitative research that supplies many graphs and data related to the main problem.

\section{The Idea of Lasting Sustainable Development}

The development of water management in Poland, among others in the areas of water regions, includes ensuring sustainable economic development understood as a balance between economic, social, and environmental aims. A crucial link between these actions is to create a social responsibility and a broad understanding of the challenges undertaken in the aspect of rational and effective flood protection.

The economy should therefore be based on three key pillars:

- Knowledge and innovation (intelligent development).

- Effective use of available resources (sustainable development).

- A high level of employment and social cohesion (inclusive development) ${ }^{1}$.

The concept of inclusive development, which is derived from the term "social inclusion," means development that favors reducing poverty and social exclusion as understood in a broad sense [1].

The principles of general rights and obligations arising from the Declaration of Rio de Janeiro on the

1 The term inclusive development (from the term "social inclusion") is understood as development that favors limiting poverty and social exclusion as broadly understood.

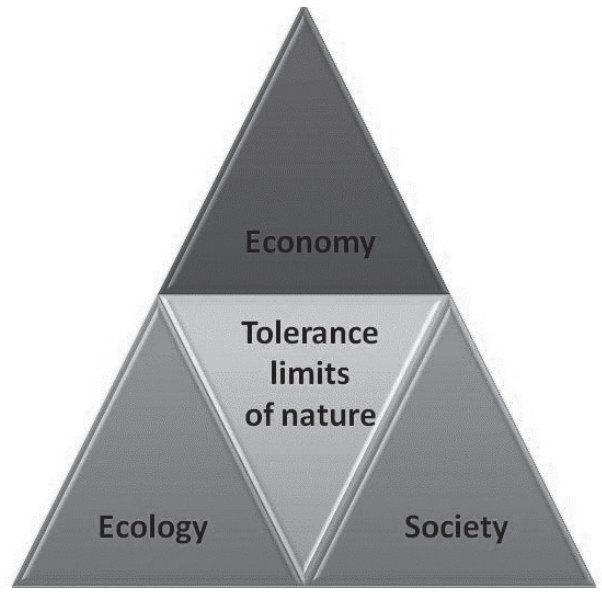

Fig. 1. The triangle of sustainable development goals. Source: own materials

Environment and Development from June 1992 constitute a substantive complement to the topic at hand.

Environmental economics, taking into account sustainable development, aims to ensure that all people living today as well as future generations sufficiently enjoy high environmental, economic, and socio-cultural standards within the limits of the natural carrying capacity of their ecosystems by applying the principle of intra-generational and intergenerational justice [2].

Fig. 1 shows the triangle of sustainable ecological development goals, which includes not only the socialization of the decision-making processes, but also the socio-cultural dimension of the future society. Within the three main goals, ecology, economy, and society, the philosophy of modern city management has been included, as a balanced set of orders, such as: the natural order in terms of the whole region, socio-demographic order for the city, and economic order, which takes into account the acceptability of actions taken as well as spatial order in terms of spatial management and intelligent urban solutions.

The complementary principle of environmental effectiveness and economic efficiency is also an important additional issue that applies to the selection of planned investment projects aimed at protecting the environment (or, more broadly, projects requiring funding), and then, during and after their completion, to evaluate the achieved results. In practice, this means the need to minimize the expenditure per unit of the effect achieved. The rank of the issue at hand is strengthened by the Environmental Protection Act in conjunction with Article 5 of the Polish Constitution, which indicates the obligation to protect the environment and to implement the principles of sustainable development, as well as Article 74, which states that environmental protection is the responsibility of public authorities and the bill in terms of the issue discussed in the article related to the transposition of the Water Framework Directive 2000/60/EC of the European Parliament and of Directive 2007/60/EC of the European Parliament and of the Council of 23 October 2007 on the 
assessment and management of flood risk constitutes its complementation.

To summarize, the main objectives of balanced and sustainable development are:

- To increase of the quality of human life.

- Eradicate poverty and reduce differences in the quality of lives of most people in the world while striving to meet their needs.

- Universal access to information concerning the environment and the opportunity to participate in decision-making.

- Promote appropriate patterns of consumption and production.

- To better use natural and renewable sources of energy.

- Environmental protection for development.

Moreover, in the field of flood risk the most effective way to ensure the safety and protection in the event of a great water threat [3].

\section{The Consequences of Floods and Flood Risk}

Flood events and great water involve damage that covers a much larger area than that directly affected by flooding, and the period of their impact is much longer than the duration of the flooding. Some examples could be the damage resulting from production constraints occurring due to damage to energy, transport, and telecommunication infrastructure, or the loss of profits caused by transportation difficulties, interference in the market after a flood (e.g., an increase in the price of food, a decline in property prices in the flooded areas), the need to reduce production leading to the loss of competitiveness of selected industries or regions, and reducing demand on the market affected by the flood [4].

The areas where floods can occur are determined, among others, by the Regional Water Management Board, as part of governmental administration. Based on these designated areas, flood hazard and flood risk maps have been created.

Flood risk maps show the potential adverse effects of flooding, whereas flood risk management plans specify a catalogue of measures aiming at achieving the objectives of flood risk management. In Poland, the preparation of these documents is the responsibility of the Ministry of the Environment and supervised entities (National Water Management and the Institute of Meteorology and Water Management) [5].

Flood risk maps are complementary to flood hazard maps in determining the value of potential losses and identifying structures prone to flooding in the event of a flood of a certain probability of occurrence. In recent times, on the basis of the above studies and collected data, flood risk management plans for a river basin and water regions have been prepared. The aim of these plans is to reduce the potential negative consequences of flooding for human life and health, the environment, cultural heritage and economic activities through the implementation of selected measures to minimize the identified risks. In the longer term, it is assumed that flood risk assessment will be modified and adapted to the changing conditions in the river basin, including those related to climate change or the frequency of flooding.

Protection against floods is the task of the government administration as well as of the local government. On that account, cooperation with local governments is an important element in planning and implementing the measures aiming at reducing the risk of flooding. With the growing awareness of citizens and the growing involvement of local government officials and representatives of the Regional Board, thanks to the flood risk management plans and flood risk maps it is possible to minimize more effectively the effects of potential flooding [6].

A municipality, when adopting planning documents such as the study of conditions and directions of urban planning, a local development plan issuing a decision concerning the location of a public interest investment as well as issuing a decision concerning conditions for construction must take into consideration the areas of special flood hazards as defined by the appropriate director of regional water management board.

The following areas of special flooding hazard should also be looked into in light of the topic at hand:

- Areas where the probability of flooding is low and amounts to once every 500 years.

- Areas where the probability of flooding is average and amounts to once every 100 years.

- Areas where the probability of flooding is high and amounts to once every 10 years.

- Areas of imminent flooding risk designated in flood protection studies.

- Areas of inter-embankment on other sections of rivers.

- Technicalbelt.

The amendment of regulations specifies that the costs of introducing changes to the planning documents will be covered by the municipalities and the provinces. Maps were developed under the IT system of the country's Protection Against Extreme Hazards Project (ISOK) by the Consortium of the National Water Management along with the Institute of Meteorology and Water Management Research Institute plus the National Institute of Geological and Governmental Crisis Management Team.

Preliminary Flood Risk Assessment (WORP) is the first of four planning documents required by Directive 2007/60/EC of the European Parliament and of the council from 23 October 2007 on the assessment and management of floods, in short called the Flood Directive.

The aim of the preliminary flood risk assessment is to determine the areas at risk of flooding or areas where there is a significant risk of flooding, or where occurrence is likely. The preliminary assessment is made based on available or easily obtainable information.

It should be emphasized that the areas designated in the preliminary flood risk assessment do not constitute a basis for spatial planning. The aim of WORP is not to determine the precise range of areas at risk of flooding, but their initial identification in order to select the rivers that pose a flood threat [5]. 
The flood risk management plans and flood risk maps prepared by Regional Water Management make it possible to minimize the risk of flood damage occuring in Poland. Due to the increasing frequency of floods in the European Union, the European Parliament has adopted the Flood Directive. The obligations imposed on the member states under the said directive involve, among other things, developing flood risk maps and flood risk management plans and making them accessible to the public.

The main objective of the authors, however, is to indicate precise mathematical methods for a more effective support system of flood risk management in reducing the potential socio-economic consequences through the introduction and ultimately the use of the probabilistic tools described in this article, allowing for a very realistic estimation of areas and the possibility of flood risk.

\section{Probabilistic Tools Used in Flood Risk Analysis}

\section{Applying Probabilistic Models for Extreme Values in Environmental Analysis: a Literature Review}

The use of statistical models and modeling techniques in determining and identifying environmental hazards is widely used in environmental engineering and is a popular tool for engineering in broad environmental management [7].

The very rich and comprehensive bibliography of the literature on the theory of extreme value distributions and their applications consists of more than 1,100 positions counting from the beginning of the 20th century until the beginning of the 21 st century. There is no way to present them all as it would require a separate multi-volume monograph devoted solely to the subject study. Such a vast literature indicates a great interest in this field of science as well as its wide application. Therefore, in this chapter, only selected items will be presented that, in our opinion, had a significant impact on the development of the theory and that are closely related to the issues raised in the article.

Probably the first to use the extreme values in studying floods in his article was Fuller [8]. The systematic development of a general theory of extreme values, however, is associated with the work of Bortkiewicz, which concerned the distribution range in a random sample from a normally distributed population. This work is very important, since the author introduced and clearly defined the concept of distribution of the highest value there for the first time [9].

Gumbel first drew the attention of engineers and statisticians on the possibility of using the formal theory of extreme values for certain distributions that were previously regarded as empirical. He applied the distribution of extreme value to the analysis of stream flows in the United States in 1941 [10]. In the course of his research, Teodorovic acquired the observed frequencies
$\mathrm{N}(\mathrm{T})$, meaning the number of days in a period (which was $\mathrm{T}$ days long) when the water flow in the Greenbrier River in West Virginia exceeded 17,000 feet ${ }^{3}$. The period of his observation took 72 years, from 1896 to 1967 . He then compared the observed frequency with the theoretical Poisson distributions. In the results it could be seen that the discrete observations N(T) for the studied river and for the given climate can be very well modeled with Poisson distributions [11].

In the 1970s-90s a lot of papers were written on the subject of applying elements of the extreme value theory to solve problems associated with floods. Pericchi and Rodriguez-Iturbe conducted research based on data on daily water flows in the Feather River in Oroville, California, USA using 1902-1960 data. From these data they selected the annual flow peaks and fitted the Gumbel distribution to their empirical distribution. In addition, in their work they proposed schedules such as: gamma (Person type III), gamma-log (log-Pearson type III), and log-normally for the analysis of selected peaks. The use of probability distributions for the flood frequency estimation was also illustrated by Greis and Wood [12]. Rossi proposed a two-component extreme value distribution to analyze the frequency of flooding. At the end of the 20th century, after the great flood in the U.S. that caused huge losses in the Midwest, Hipel presented the use of extreme value theory in the analysis of flood events in his work. He presented a thorough analysis of emergency levels exceeding 100 years in the context of the flood of 1993.

In their article, Katz with co-authors presented a comprehensive study using distributions of extreme values on hydrological data collected in Fort Collins, Colorado, USA [13]. Engeland, Frigessi, and Hisdal presented the analysis of flood and drought risks using the generalized extreme value distributions and Pareto. They conducted their research on data concerning stream flows on the Ha river in southwestern Norway [14]. In their work, Bordi, along with co-authors, analyzed wet and dry periods in Sicily. For this purpose they applied monthly rainfall maxima [15]. Yurtal and others compared in their work the method of maximum likelihood to weighted method of moments for estimating the parameters of hydrological data distribution probability obtained from measuring stations on the Ceyhan river in southern Turkey [16]. After a great number of floods in the Czech Republic, Holičky and Sykora used log-normal distributions and Persona III in their research to estimate the flood risk for cultural heritage [17]. Nachabe and Paynter conducted research using generalized distribution of extreme values on hydrological data from the selected lakes in southwestern Florida [18]. Chaibandit and Konyai, in their studies, analyzed hydrological data obtained on a monthly basis from six stations on the Yom River. The study used the distributions of extreme values, normal distribution, and log-normal distribution as well as the return period method [19]. Arns and others, in their studies, estimated flood risk by estimating the probability of achieving a certain water level in rivers [20]. Charon, along with other 
scientists in their work, compared a very large number of probability distributions used to model wind speeds. The data came from nine meteorological stations in the United Arab Emirates [21].

At this point we should rely on [22-24].

One of the co-authors of this study, has been conducting research on the probabilistic measurement of flood risk in Lower Silesian rivers since 2010. The results of these studies are presented in the following works [2531].

Since 2015 the authors have been conducting research on the measurement of flood risk dynamics in the rivers of Lower Silesia using selected models of extreme value distributions. The results of these studies are presented in [32-34].

\section{Maxima}

We assume that the $y_{i}$ observations are the maxima, i.e., that:

$$
y_{i}=\max \left\{x_{i 1}, \ldots, x_{i m}\right\}, \quad i=1, \ldots, n,(1)
$$

...where $x_{i j}$ may not be observable. In the case where $x_{i j}$ are observable, the selection of certain maxima from certain sets with $m$ number of elements is a form of selection of the upper extreme values from a data set. This method is called the block or Gumbel method [28].

The block maxima method requires defining the time horizon (the block) and calculating the maxima of the tested variable for the said horizon. Most commonly, blocks of one year, half a year, quarter, month, or smaller size are used depending on research needs. For data in the form of hydrometric parameters blocks of the size mentioned above are used. The block size cannot be too small to prevent the occurrence of the relationship between the maximum values of the neighboring blocks of time. A 10-day period is considered to be the minimum limit value of the size of the time block for which the independence of neighboring maxima can be accepted [14].

There can also be cases when, during long-lasting floods, there may occur a risk of dependence even between the maxima of adjacent blocks of time. In such situations when such a relationship between the variables under consideration occurs, it is necessary to apply the cumulative distribution of extreme values for dependent random variables for the analysis of the distribution of the maximum values [23].

At this point, one more fact deserves attention, namely that the observations $y i$ are the embodiments of the random variable $M_{m}$ defined by the formula:

$$
M_{m}=\max \left\{X_{1}, \ldots, X_{m}\right\} \text {. }
$$

In the studies conducted for the purposes of this article we used a 31-day block (for simplicity referred to as a "monthly" block).

\section{Probabilistic Models of Maxima Values}

In the probabilistic studies of maxima distributions for hydrometric data it is suggested to first apply the Gumbel distribution, which is one of the three types of extreme value distributions [35]. A U.S. Interagency Advisory Committee on Water Data - Hydrology Subcommittee (IACWD; 1983) report recommends Persona III distribution with the log-normal transformation for longterm data to predict flooding events as well as log-normal distribution.

According to the theorem concerning the types of extreme value distributions, the distributions of extreme values are described by one of three distribution functions from the family of extreme value distribution functions [36]. Additionally, if random variable X has the distribution function $\mathrm{F}$, then the random variable $(\mu+\sigma \mathrm{X})$ has the distribution function where $\mathrm{m}$ and $\mathrm{s}>0$ are the parameters of position and scale, respectively. Combining the above two statements together results in a very broad family of distribution functions for extreme values distributions defined by the following formulas:

Gumbel (EV0 or Type I)

$$
G_{0}(x)=\exp \left(-e^{-(x-\mu) / \sigma}\right),-\infty<x<\infty
$$

Frechet (EV1 or Type II)

$$
G_{1}(x)=\exp \left(-\left(\frac{x-\mu}{\sigma}\right)^{-\alpha}\right) \text {, for certain } \alpha>0, x>0
$$

Weibull (EV2 or Type III)

$$
\begin{gathered}
G_{2}(x)=\exp \left(-\left(-\left(\frac{x-\mu}{\sigma}\right)\right)^{\alpha}\right), \\
\text { for certain } \alpha>0, x \leq 0
\end{gathered}
$$

Broadening the classic family of distribution functions of the extreme values distributions by the parameters of position and scale, as has been done and presented in models 3-5, significantly expands the spectrum of possibilities related to the modeling of the maximum value distributions of various random variables. Taking advantage of parameterized distribution functions of the maximum values distributes a theoretical distribution function that describes the distribution of the studied value of the maximum characteristic at a very large degree of compliance that can be very precisely matched.

In our research here a tool in the form of empirical distribution function was used to visualize empirical 
distributions of the maximal values of specific hydrological characteristics.

\section{Estimation Methods and Tests of Significance}

To estimate the parameters of the maximum values distributions from the family of distribution functions of the distributions described with formulas (3-5), for the purpose of research, the maximum likelihood method was applied .This method gives effective results in specific cases. These cases concur with the cases considered in this study [37]. The parameter yestimator exists for $\gamma>-1$ and for $\gamma>-0.5$ the variance has asymptotically normal distribution.

In order to verify the hypotheses concerning the compatibility of the studied empirical distributions with the selected theoretical distributions of maximal values described in our paper, the following compliance tests were applied: chi-square, Kolmogorov-Smirnov, and Anderson-Darling. In addition, within the family of distributions of extreme values described by formulas (3-5), the credibility quotient test is used to verify the hypothesis $\mathrm{H} 0: \mathrm{g}=0$, i.e., that the tested distribution is better described by Gumbel distribution, against an alternative hypothesis $\mathrm{H} 1$ : that the tested distribution is better tested by other distributions of this family. The test statistics for this test are described with the formula:

$$
T_{\mathrm{LR}}(x)=\frac{\prod_{i \leq n} g_{\hat{\gamma}, \hat{\mu}, \tilde{\sigma}}\left(x_{i}\right)}{\prod_{i \leq n} g_{0, \tilde{\mu}, \tilde{\sigma}}\left(x_{i}\right)}
$$

...from $(\hat{\gamma}, \hat{\mu}, \hat{\sigma})$ and $(\tilde{\mu}, \tilde{\sigma})$ representing the sets of the maximal likelihood estimators in the EV0, EV1, and EV2 models described by formulas (3-5). Since the sets of parameters are 2- and 3-dimensional, it is known that the test statistics have an asymptotically chi-square with 1 degree of freedom. Consequently, p-value has the formula:

$$
p_{\mathrm{LR}}(x)=1-\chi_{1}^{2}\left(T_{\mathrm{LR}}(x)\right)
$$

The significance level is achieved with higher accuracy using Bartlett's adjustment, which consists of replacing the TLR test statistics with the statistics given by the TLR formula/ $(1+2.8 / n)$. In this case, the $p$-value has the formula:

$$
\begin{gathered}
p_{\mathrm{LR}}(x)=1-\chi_{1}^{2}\left(T_{\mathrm{LR}}(x) /(1+2.8 / n)\right) \\
\text { Analysis of the Flood Risk Dynamics } \\
\text { - Experimental }
\end{gathered}
$$

\section{Analysis of the Flood Risk Dynamics - Experimental}

\section{Hydrological Data}

In a study conducted for the purpose of this article one of the hydrometric parameters was used, which is the flow measured in units of $\mathrm{m}^{3} / \mathrm{s}$ [38]. The daily flows for the Odra measured at hydrological stations located in Malczyce were collected for the study in the time period 01.01.1994 to 31.12.2013, which gives a sample size of $n=7,305$. The time horizon studied was divided into four periods of a length of five years each: period I spans 199498, period II spans 1999-2003, period III spans 2004-08, and period IV spans 2009-13.

Using the block method described in the previous section, 30-day maxima were selected from the daily flows. With these assumptions, formula (1) takes the form:

$$
y_{i}=\max \left\{x_{i 1}, \ldots, x_{i 30}\right\}, \quad i=1, \ldots, 60
$$

... for the maxima of the tested data for each of the four periods.

\section{Theoretical and Empirical Probabilistic Models for Maxima}

To depict the empirical probability distributions of the 30-day maxima in the four studied periods we used a commonly used tool in the form of an empirical distribution function. Additionally, the chart of the empirical distribution function for each period includes a distribution function of an optimally matched distribution of the theoretical maxima. These graphs are shown in Fig. 1.

In the data from period I (1994-98) there is one maximum $q_{\mathrm{VII}, 97}=3,020 \mathrm{~m}^{3} / \mathrm{s}$ from July 1997 , when the historical flood in the Oder basin took place. The graph for period I (see Fig. 1) shows an empirical distribution function that was removed without this observation. For comparison, Fig. 2 shows a graph of an empirical distribution function for data from period I, including all the maxima with the optimally matched theoretical distribution function.

By using the highest likelihood method, we estimated the parameters of theoretical distribution optimally suited to the empirical distributions of the studied maxima for the four periods. In the case of period I, we estimated the maxima distribution parameters excluding and including the observation of the $q_{\mathrm{VII}, 97}=3,020 \mathrm{~m}^{3} / \mathrm{s}$ maximum.

In the case of period I excluding the $q_{\mathrm{VII}, 97}$ maximum observation and of period II the Gumbel distribution, the distribution function described by Formula (3) turned out to be the optimally suited distribution for the empirical distribution of the 30-day flow maxima. For period I including the $q_{\mathrm{VII}, 97}$ maximum observation as well as for period III and period IV Frechet distribution, the distribution function of which are described with Formula (4) turned out to be the optimally suited distribution.

The charts of the empirical distribution functions of the studied maxima for the periods under consideration along with the theoretical distribution functions of the respective distributions indicate a very good fit of the theoretical distributions (Figs 1-2). In order to confirm the goodness of fit of the empirical distributions with the 

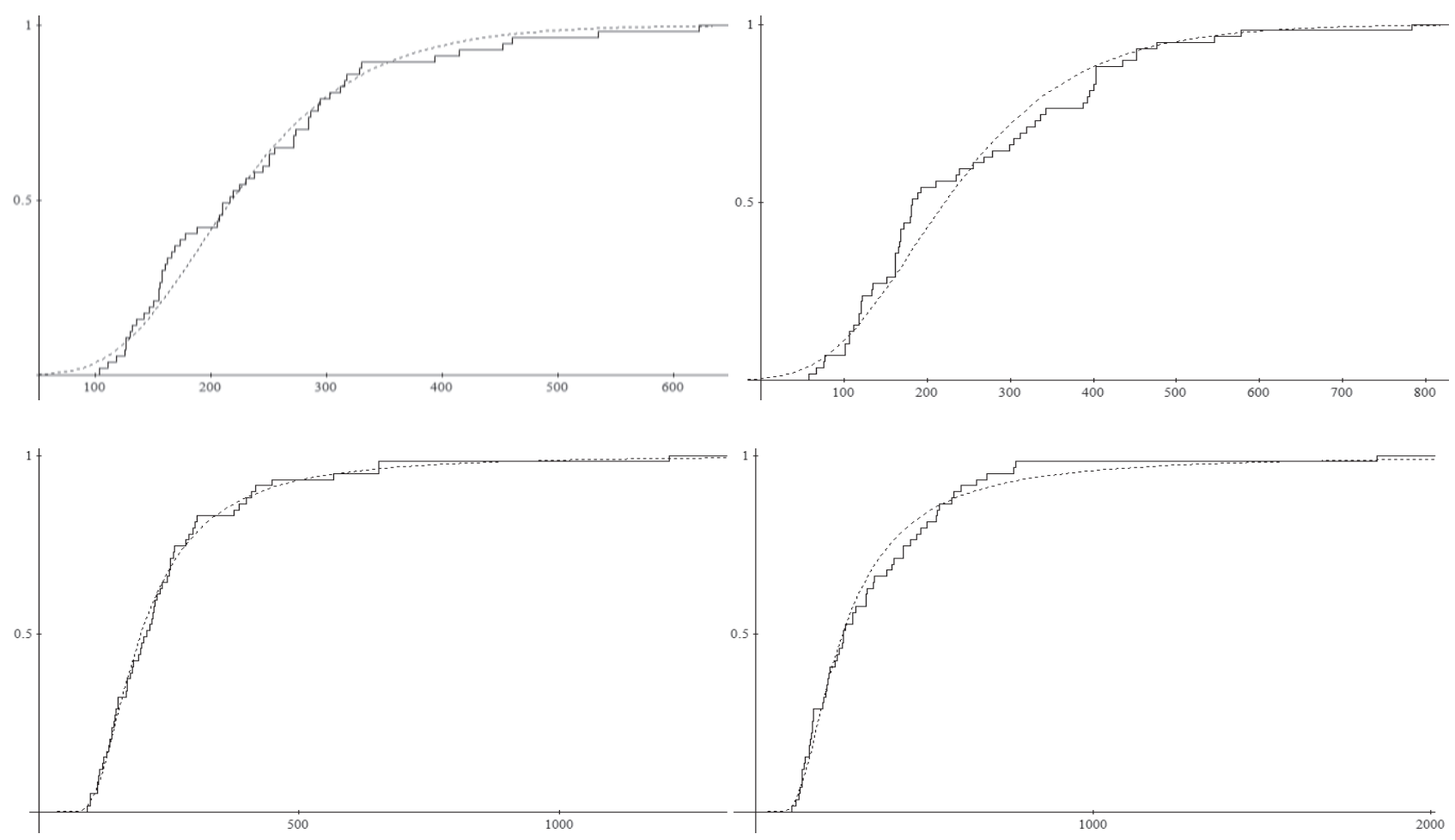

Fig. 2. The empirical distribution functions of 30-day flow maxima distributions for the data from Malczyce for periods I-IV (solid line) and the distribution functions for the theoretical maxima distributions (dotted line). The chart in the upper left corner is period I, the chart in the upper right corner is period II, the chart in the bottom left corner is period III, and the chart in the lower right corner is period IV. Source: own materials.

matched theoretical distributions resulting from a visual assessment of the given distribution function graphs, the following commonly used goodness of fit tests were performed: Anderson-Darling and Kolmogorov-Smirnov. The results of the tests for the distribution in all the analyzed periods in the form of $p$-value are shown in Table 2, which confirms a very high goodness of fit of the chosen theoretical distributions with the corresponding empirical distributions.

In addition, to confirm the validity of choosing the appropriate distributions of extreme values for the respective studied periods, a likelihood ratio test within the family of distributions of extreme values described with Formulas (3-5) was conducted, which was described

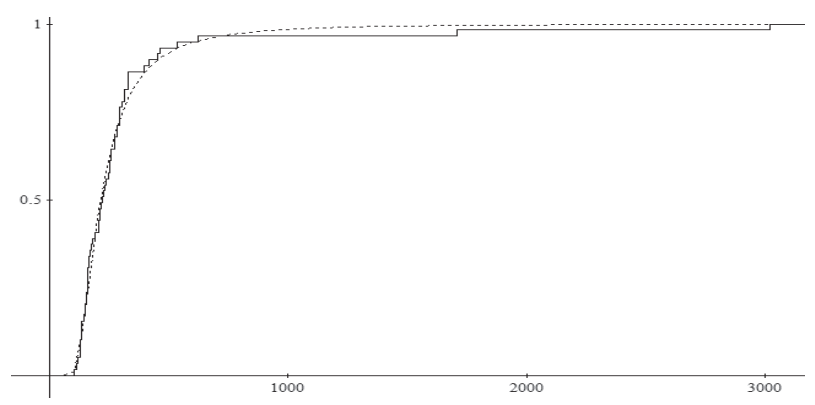

Fig. 3. The empirical distribution function of maxima distributions for period I, including data from July 1997 (solid line) and the distribution function of theoretical distribution. Source: own materials. previously. Values of $p$-value calculated from Formula (8) are presented in Table 3.

\section{Risk Assessment of Flood Risk in the Analyzed Periods}

This section consists of two main parts. In the first part, flood risk measures will be calculated in the studied periods. The second part of the section contains an analysis of the dynamics of the examined risk.

Defining the concept of risk proves to be a difficult time every time. Providing a clear, precise definition is impossible. Risk is defined on the basis of various branches of knowledge and theories, including

Table 1. Values of the estimators of the theoretical distribution parameters for the flow maxima for the studied periods.

\begin{tabular}{|c|c|}
\hline Periods & The estimatorsvalues \\
\hline 1994-98 excluding $q_{\mathrm{VII}, 97}$ & $\hat{\mu}_{I}=190.5 \quad \hat{\sigma}_{I}=74.3$ \\
\hline 1994-98 including $q_{\mathrm{VI}, 97}$ & $\hat{\mu}_{I}=0 \hat{\sigma}_{I}=183.5 \alpha=2.463$ \\
\hline $1999-2003$ & $\hat{\mu}_{I I}=182.85 \hat{\sigma}_{I I}=105.42$ \\
\hline $2004-08$ & $\hat{\mu}_{I}=0 \hat{\sigma}_{I}=129.1 \alpha=2.824$ \\
\hline $2009-13$ & $\hat{\mu}_{I}=0 \hat{\sigma}_{I}=215.2 \alpha=2.04$ \\
\hline
\end{tabular}

Source: own materials. 
Table 2. p-value values of the compatibility tests for maxima distributions.

\begin{tabular}{|c|c|c|}
\hline $\begin{array}{c}\text { Test } \\
\text { Period }\end{array}$ & KS & A - D \\
\hline 1994-98 excluding qVII, 97 & $p_{v}=0.6208$ & $p_{v}=0.7998$ \\
\hline 1994-98 including qVII, 97 & $p_{v}=0.763$ & $p_{v}=0.8429$ \\
\hline $1999-2003$ & $p_{v}=0.6271$ & $p_{v}=0.5849$ \\
\hline $2004-08$ & $p_{v}=0.9776$ & $p_{v}=0.9918$ \\
\hline $2009-13$ & $p_{v}=0.6208$ & $p_{v}=0.7998$ \\
\hline
\end{tabular}

Source: own materials.

Table 3. p-values for the likelihood ratio test in the family for extreme values distributions.

\begin{tabular}{|c|c|}
\hline Periods & p-value \\
\hline 1994-98 excludingqVII, 97 & $p_{v}=0.128$ \\
\hline 1994-98 includingqVII, 97 & $p_{v}=0.000$ \\
\hline 1999-2003 & $p_{v}=0.115$ \\
\hline $2004-08$ & $p_{v}=0.000$ \\
\hline $2009-13$ & $p_{v}=0.000$ \\
\hline
\end{tabular}

Source: own materials.

economics, behavioral sciences, legal sciences, psychology, statistics, insurance, probability theory, and others. According to the authors, the following two definitions of risk are most suitable for determining flood risk. The first one treats risk as the possibility or likelihood of loss, e.g., due to flooding [39]. The second definition assumed the risk to be the probability of a system failure or the failure of its $p_{\mathrm{f}}$ element which, in particular cases, may be equated with flooding [40].

In this paper, based on the aforementioned two definitions, the probability of exceeding a certain water flow level $(q)$ by the maximal daily water flow from the time horizon assumed in the study was adopted as the measure of flood risk in the studied area. The time horizon of 30 days was chosen for the purpose of this study.
To measure the risk we chose maximal water flow from the flood from June 2010, namely $q_{\mathrm{VI}, 2010}=$ $1,840 \mathrm{~m}^{3} / \mathrm{s}$. According to Formula (2), the maximum 30-day flow is a random variable denoted by $M 30$. Table 4 presents the results of calculations of risk measurements constituting the probability to exceed the flow $q_{\mathrm{VI}, 2010}$ by a random variable $M_{30}$ for all studied periods.

Additionally, Table 4 contains the indexes of the dynamics of changes in flood risk over the period 1 994-2013. The results clearly show a strong upward trend in risk. The flood risk in period II in comparison to period I increased by as much as $645 \%$, during period III in relation to period II it increased by 3,691\%, and in period IV compared to period III by $2,163 \%$.

\section{Discussion}

The article is based on an innovative solution. Due the authors creating unique flood risk measures we took into account mathematical-statistical tools that were not widely known and used for analyzing the literature. In order to improve the actions due flooding this kind of tool might be very useful. The first part of the article analyzed the flood risk assessment for a period of 30 years. The second part of the article was based on positivistic scientifically articles and implemented to author a unique method of measurement.

\section{Result and Conclusions}

Poland's water resources are among the lowest in Europe, and are also characterized by uneven temporal and spatial distribution. In addition, climate change contributes to the increasing occurrence of maximum flows in rivers. Inadequate land management and unjustified belief in the effectiveness of technical flood control measures can contribute to flood damage. Sustainable water management should be implemented through the integration of social, environmental, and economic objectives [41-42].

The factors described in our paper include environmental protection requirements, while the

Table 4. Measurements of flood risk for the Oder River in Malczyce.

\begin{tabular}{|c|c|c|c|}
\hline Riskmeasure & $P\left(M_{30}>q_{\mathrm{VI}, 2010}\right)$ & Dynamics indexesIt/t-1 & $\begin{array}{c}\text { Percentilechanges } \\
+/-\end{array}$ \\
\hline Periods & 0.0000002 & - & - \\
\hline 1994-98 excludingqVII, 97 & 0.003414655 & - & 645 \\
\hline II: $1999-2003$ & 0.000001490 & 7.45 & 3,691 \\
\hline III: $2004-08$ & 0.000551176 & 369.1 & 2,163 \\
\hline IV: $2009-13$ & 0.012475177 & 22.63 & - \\
\hline
\end{tabular}

Source: own materials. 
appropriate planning serves to program and coordinate actions to achieve or maintain good (at least) ecological status through continuous improvement of environmental resources, taking into account measurements to reduce flood risk in the Odra River basin. Sustainable development is therefore a set of orders such as: natural, socio-demographic, economic, and spatial.

The activities aimed at achieving ecological and economic effectiveness apply when choosing the methodology of implementing planned environmental protection and flood risk management projects.

Flood protection measures should primarily use solutions that are the least invasive for the natural environment, especially non-technical flood protection methods (e.g. flood risk assessment and management, appropriate flood planning, and development). Undoubtedly, the basis for planning in water management is the preparation of models and, subsequently, determining the probability of the occurrence of maximum flows.

Three action instruments can create an integrated flood safety system:

- Investment engineering.

- Economic engineering.

- Financial engineering.

Investment engineering is not the only recipe for flood safety, since an integrated investment, economic, and financial approach gives a sense of security to the public in areas directly affected by floods and adjacent areas. By applying a risk measure in the form of probability of flood hazard, the interdependence between sustainable development and economic interest is taken into account.

The use of flood risk models can be similar to a classic cash flow strategy using derivative instruments such as loans, subsidies, setting interest rates on loans, and insurance. Using a probabilistic risk assessment, soft behaviors can be followed by social behavior training to minimize flood damage.

Analysis of historical data based in the years of catastrophic floods is not a measure or forecast related to the occurrence of subsequent flooding. Using risk as a tool allows for the ability to plan anti-flood activities while allowing for secure financial resources to be liquidated. It is possible to plan the construction of adequate flood protection infrastructure in both hard and soft operations.

Probabilistic models of maximum values for selected hydrological characteristics (maximum daily flows and daily water status) provide an effective tool to support the entire flood risk management process in the context of socio-economic consequences.

Extreme value models were used in the $20^{\text {th }}$ century and are still widely used now for flood risk measurement and evaluation $[8,11,17,20]$.

On the basis of selected probabilistic models, flood risk measurements in the form of probability of exceeding certain values were calculated by the hydrological characteristics of $\mathrm{Q}(\mathrm{w} \mathrm{m} / \mathrm{s})$. Using the obtained risk measurements in the four analyzed periods, we analyzed its dynamics. The results showed a very strong upward trend of this risk.

Additionally, to illustrate the influence of the maximum flow of July 1997 (historical flood date in Poland, i.e., qVII, $1997=1,840 \mathrm{~m}^{3} / \mathrm{s}$, for period I), the risk measurement was calculated based on a model in which parameters were estimated without observing the maximum of 1997, and the same measurement was calculated on the basis of a model estimated on the basis of a complete data set. Significant differences in the results shown in Table 4 show how the extreme impact the observations exerted on the model. In flood risk dynamics analysis, the result obtained from the model without qVII, 1997 was taken.

Widespread multidimensional flood models used in the United States and Europe are characterized by large computational space and extended analysis of results. On the other hand, using a probabilistic measurement of risk is undoubtedly a complement to global analysis and directions of flood control. Not only do both models complement each other, but they can also be calibrated for data quality.

Reinforcing flood risk management plans and flood hazard maps into tools in the form of probabilistic flood risk measurements will allow for extensive spatial and temporal planning.

Analysis of risk dynamics allows for timely updating of the planning documents described above.

\section{Acknowledgements}

This article was based on the flood risk dynamics on the Oder River with socio-economic assessment and suitable development by the authors Prof. Jerzy Zwiździak and Dr. Lukasz Kuźmiński. The authors cooperated and shared knowledge with a few educational institutions that delivered crucial information. Furthermore, the authors of this article created it with the cooperation of three educational research institutions: Wrocław University of Technology, the University of Economics in Wrocław, and the Institute of Meteorology and Water ManagementNational Research Institute. Without their participation this article could not have been finished.

\section{References}

1. IDCZAK P. Peripheral regions development path. Globalization and regionalization in the modern world.: E. Molendowski, 168-177: Wydawnictwo Uniwersytetu Ekonomicznego w Krakowie, Kraków 2012.

2. ROGALL H. The economics of sustainable development - theory and practice. Wydawnictwo Zysk i S-ka, Poznań 2010.

3. SZAŁATA $Ł$. Model for the Lower Silesia sustainable development dialogue. Legnica: Wydawnictwo Edytor, 2015.

4. KUŹMIŃSKI Ł., SZAŁATA Ł., ZWOŹDZIAK J. Application of the elements of extreme value theory to 
assess the dynamics of flood risk in the Odra River basin on the example of the hydrological station in Trestno. Rocznik ochrony środowiska 18 (2), 972.

5. www.kzgw.gov.pl. (20.06.2016)

6. PRZEŹDZIECKI R. „Www.bezpieczenstwopubliczne.pl.” 29 grudzień 2015. http://www.bezpieczenstwopubliczne.pl/ aktualnosci/1387,0,8,,mapy_ryzyka_powodziowego_minimalizuja_skutki_kleski.html (20.06.2016).

7. ZWOŹDZIAK J. Contemporary trends in atmospheric air quality management. Państwowy Instytut Badawczy IMGW, Warszawa, 2017.

8. FULLER W. Floods flows.Trans. Amer. Soc. Civil Engineers 77, 564, 1914.

9. BORTKIEWICZ L. Variationsbreite und mittlerer Fehler. Sitzungsber Berli. Meth. Ges. 21 (1), 3, 1922.

10. GUMBEL E. The return period of flood flaws. Ann. Math. Statist. 12, 163, 1941.

11. TODOROVIC P., A probabilistic approach to analysis and prediction of floods, Proc. $43^{\text {rd }}$ ISI, 1979.

12. GREIS N., WOOD E. Regional flood frequency estimation and network design.Water Resources Res., 1167, 1981.

13. KATZ R., PARLANGE M. I NEVEAU P. Statistics of extremes in hydrology. Advances in Water Resources, 8, 2002.

14. ENGELAND K., FRIGESSI A., HISDAL H. Practical Extreme Value Modelling of Hydrological Floods and Droughts: A Case Study.Extremes, 7 (1), 5, 2005.

15. BORDI I., FRAEDRICH K., PETITTA M. I SUTERA A. Extreme value analysis of wet and dry periods in Sicily. Theor. Appl. Climatol. 87, 61, 2007.

16. DOGAN A., HAKTANIR T., SECKIN S., YURTAL R. Comparison of propability weighted moments and maximum likehood methods used in frequency analysis for ceyhan river basin. Arabian Journal for Science \& Engineering, April, 35 (1B), 49, 2010.

17. HOLICKY M., SYKORA M. Assessment of Flooding Risk to Cultural Heritage in Historic Sites. Journal of perfomance of constructed facilities, 432, 2010.

18. NACHABE M., PAYNTER S. Use of generalized extreme value covariates to improve estimation of trends and return frequencies for lake levels.Journal of Hydroinformatics $\mathbf{1 3}$ (1), 13, 2011.

19. CHAIBANDIT K., KONYAI S. Using Statistics in Hydrology for Analyzing the Discharge of Yom River. APCBEE Procedia, 1, 356, 2012.

20. ARNS A., WAHL T., HAIGH I., JENSENA J., PATTIARATCHI C. Estimating extreme water level probabilities: A comparison of the direct methods and recommendations for best practice. Coastal Engineering 81, 51, 2013.

21. CHARON C. Probability distributions of wind speed in the UAE. Energy Conversion and Management 93, 414, 2015.

22. WDOWIKOWSKI M., KAŹMIERCZAK B., LEDVINKA O., Maximum daily rainfall analysis at selected meteorological stations in the upper Lusatian Neisse River basin, Meteorol. Hydrol. Water Manage., 4 (1), 53, 2016. (The scope of this study was to assess the usefulness of top probability distributions to describe maximum rainfall data in the Lusatian Neisse River basin, based on eight IMGW- National Research Institute meteorological stations. To describe the measured data, there were used the Fréchet, Gamma, Generalized Exponential Distribution (GED), Gumbel, Log-normal and Weibull distributions.)
23. KUCHAR L., IWAŃSKI S., JELONEK L., SZALIŃSKA W., 2014, Application of spatial weather generator for the assessment of climate change impacts on a river runoff, Geografie, 119 (1), 1, 2014. (3-parameter gamma distribution was found as the best fitting monthly, seasonal and annual distributions of daily runoff basing on K-S and Chi-Square tests.)

24. BANASIAK R., KRZYŻANOWSKI M., Flood Flows in the Odra River in 2010 - quantative and qualitative assessment of ADCP data, Meteorol. Hydrol. Water Manage., 3 (1), 11, 2015. (The analysis is that the previously estimated flow risk and peak discharge values for the 2010 flood published previously were underestimated and the final conclusion is that the modern field data acquisition, GIS post processing, and numerical modelling, support each other and improve the final overall result, bringing hydrology products to a higher standard than they would do separately.)

25. KUŹMIŃSKI Ł. Application of the extreme value theory in warning forecasting for a sequence of independent variables with a normal distribution. Application of quantitative methods in economic sciences. Zeszyty Naukowe wyższej Szkoły Bankowej we Wrocławiu 2 (34), 2013.

26. KUŹMIŃSKI Ł. Limits distribution of extremes in warning forecasts of water levels. Zarządzanie i Finanse 3 (2), 147, 2013.

27. KUŹMIŃSKI Ł. Distributions of extreme values in the analysis of hydrological hazard in Lower Silesia. Quantitative methods in economics. Zaszyty naukowe $\mathrm{nr}$ 811, 305, 2013. Wydawnictwo Naukowe Uniwersytetu Szczecińskiego.

28. KUŹMIŃSKI Ł. The use of Poisson distribution to assess the risk of hydrological hazard. Mathematical and econometric methods in finance and insurance. Zeszyty Naukowe Wydziałowe 206, 7, 2013. Wydawnictwo Uniwersytetu Ekonomicznego w Katowicach.

29. KUŹMIŃSKI Ł. Functions of excess and hazard as a tool in the analysis of flood risk in Lower Silesia. Quantitative methods. Zeszyty naukowe Wyższej Szkoły Bankowej we Wrocławiu 7 (45), 207, 2014. Wydawnictwo Wyższej Szkoły Bankowej w Poznaniu.

30. KUŹMIŃSKI $Ł$. The use of Poisson distribution to assess the risk of hydrological hazard. Mathematical and econometric methods in finance and insurance. Zeszyty Naukowe Wydziałowe 206, 7, 2014.

31. KUŹMIŃSKI Ł. Positional statistics in warning forecasts. Application of quantitative methods in economics and management. Red. Stefan Forlicz. Warszaw, 199, 2012.

32. KUŹMIŃSKI Ł., SZAŁATA Ł., ZWOŹDZIAK J. Application of selected probability distributions of extreme values for estimating the risk of flood hazard on the Odra River in Lower Silesia. Ochrona Środowiska 38 (3), 35, 2016.

33. KUŹMIŃSKI Ł., SZAŁATA Ł., ZWOŹDZIAK J. The reality of life during floods. Journal of Civil \& Environmental Engineering, 6 (5), 2016.

34. KUŹMIŃSKI Ł., SZAŁATA Ł., ZWOŹDZIAK J. Assessment of variability of flood risk in the Odra basin on the basis of half-yearly distribution of the maximum water levels. Prace Naukowe Uniwersytetu Ekonomicznego we Wrocławiu, 454, 102, 2016.

35. YUE S., BOBE B., LEGENDRE P.I BRUNEAU P. The Gumbel mixed model for flood frequency analysis. J. Hydrol., 88, 1999. 
36. KUŹMIŃSKI Ł. Limit distribution of extreme values for dependent sequences of random variables. Ekonometria nr 2 (29). Wydawnictwo Uniwersytetu Ekonomicznego we Wrocławiu, 2013c.

37. KOTZ S., NADARAJAH S. Extreme value distributions. Theory and Applications. London: Imperial College Press, 2005.

38. BAJKIEWICZ-GRABOWSKA E., MIKULSKI Z. Hydrology, Warszawa: PWN, 2011
39. JEDYNAK P. Economic insurance. Kraków: Księgarnia Akademicka, 2001.

40. YEN B. Stochastic methods and reliability analysis in water resources. Advances Water Resources, 11, 1988.

41. ROGALL H. Sustainable development economics - theory and practice (in Poland), Wydawnictwo Zysk i S-ka Poznań 2010.

42. ZWODŹDZIAK J. Flood risk management plans. Przegląd Komunalny. Przegląd Komunalny, 2015. 